\title{
Surgical strategy when identifying less than four parathyroid glands during total thyroidectomy: a retrospective cohort study
}

\author{
Zhichao Xing ${ }^{1 \#}$, Yuxuan Qiu ${ }^{1,2 \#}$, Baoying Xia ${ }^{1}$, Munire Abuduwaili ${ }^{1}$, Yuan Fei ${ }^{1}$, Jingqiang Zhu ${ }^{1}$, Anping Su ${ }^{1}$ \\ ${ }^{1}$ Center of Thyroid \& Parathyroid Surgery, West China Hospital, Sichuan University, Chengdu, China; ${ }^{2}$ Department of Ultrasound, West China \\ Hospital, Sichuan University, Chengdu, China \\ Contributions: (I) Conception and design: Z Xing, Y Qiu; (II) Administrative support: A Su, J Zhu; (III) Provision of study materials or patients: A \\ Su, J Zhu; (IV) Collection and assembly of data: B Xia, M Abuduwailia, Y Fei; (V) Data analysis and interpretation: Z Xing, Y Qiu; (VI) Manuscript \\ writing: All authors; (VII) Final approval of manuscript: All authors. \\ "These authors contributed equally to this work. \\ Correspondence to: Anping Su, MD. Center of Thyroid \& Parathyroid Surgery, West China Hospital, Sichuan University, No. 37 Guo Xue Xiang, \\ Chengdu 610041, China. Email: suanpingping@126.com.
}

\begin{abstract}
Background: Parathyroid glands protection is still controversial in patients with less than 4 parathyroid glands during thyroidectomy. The aim of this study was to investigate the strategy of parathyroid autotransplantation or in situ preservation in patients with 3 parathyroid glands.

Methods: Consecutive patients who underwent primary total thyroidectomy with bilateral central neck dissection for papillary thyroid carcinoma (PTC) in our center were included retrospectively. Serum calcium and parathyroid hormone $(\mathrm{PTH})$ levels $(\mathrm{pg} / \mathrm{mL})$, incidence of hypocalcemia and hypoparathyroidism during 24 months follow-up were compared grouping by the number of parathyroid glands both identified intraoperatively and confirmed postoperatively by pathology.

Results: A total of 1,424 patients were included. Serum PTH and calcium levels were lower and the incidence of hypocalcemia was higher in patients with 3 identified parathyroid glands. When excluding patients with accidental parathyroid resection, the results remained similar. Of the 212 patients with 3 identified parathyroid glands, PTH levels at postoperative 12-month in patients underwent autotransplantation were significantly lower than patients with all parathyroid glands preserved in situ $(3.65 \pm 1.30$ vs. $4.67 \pm 1.89, \mathrm{P}=0.026)$.
\end{abstract}

Conclusions: The parathyroid function was weaker in patients with 3 parathyroid glands than patients with 4 before and after operation. Parathyroid glands preserved all in situ promoted better recovery of postoperative function in patients with 3 identified parathyroid glands.

Keywords: Autotransplantation; autologous; hypocalcemia; parathyroid glands; thyroidectomy

Submitted May 06, 2020. Accepted for publication Sep 03, 2020.

doi: $10.21037 /$ gs-20-486

View this article at: http://dx.doi.org/10.21037/gs-20-486

\section{Introduction}

Over the past three decades, the incidence of thyroid cancer has increased threefold, whereas the papillary thyroid carcinoma (PTC) accounts for approximately $90 \%$ of thyroid cancer (1). Postoperative hypocalcemia and hypoparathyroidism are common complications in PTC operations due to parathyroid injury from devascularization, mechanical and thermal trauma, or resection of one or more parathyroid glands (2-5). Total thyroidectomy with central neck dissection increases the risk of postoperative hypoparathyroidism, especially with bilateral central neck dissection (6). It is reported the prevalence of transient hypocalcemia ranged from $19 \%$ to $38 \%(7)$, and the incidence of transient and permanent hypoparathyroidism were $51.9 \%$ and $16.2 \%$ after total thyroidectomy with 
bilateral central lymph node dissection, respectively (8).

Some authors believed that the parathyroid glands should be preserved in situ and autotransplantation should be limited (9), while other authors supported routine autotransplantation of one gland (10). Meanwhile, there were surgeons also believed that the adoption of parathyroid autotransplantation should be of all identified parathyroid gland or at least two of the identified glands (11). However, the number of parathyroid glands can be varied from each other. The former reached consensus or existed debate concentrating on patients with at least 4 parathyroid glands. However, it was reported that $78 \%$ of people had four of these glands, and about $15 \%$ had three (12). Previous studies had not explained about the protection strategy for patients with three parathyroid glands. In this circumstance, strategy of autotransplantation or preservation in situ for patients with three parathyroid glands is still uncertain.

Therefore, the aims of this study were to investigate the rule of parathyroid function after total thyroidectomy with bilateral central neck dissection in patients with three parathyroid glands and to ascertain whether autotransplantation affected the incidence of postoperative hypocalcemia, transient and permanent hypoparathyroidism, thereby providing evidence for the surgical strategy of patients with fewer parathyroid glands.

We present the following article in accordance with The Strengthening the Reporting of Observational Studies in Epidemiology (STROBE) reporting checklist (13) (available at http://dx.doi.org/10.21037/gs-20-486).

\section{Methods}

The study was conducted in accordance with the Declaration of Helsinki (as revised in 2013). The Institutional Review Board of West China Hospital (No. 2019-799) approved this retrospective study, and all patients provided informed consent to have their data recorded, analyzed, and published for research purposes.

\section{Patients}

We reviewed our clinical database containing 2,032 consecutive records of patients with PTC, which could reduce bias. All the patients who underwent primary total thyroidectomy with bilateral central neck dissection in the Department of Thyroid \& Parathyroid Surgery, West China Hospital, Sichuan University between January 2013 and June 2018 were included retrospectively. Inclusive criteria included patients with three or four identified parathyroid glands in operation. Exclusion criteria included (I) incomplete data; (II) reoperation; (III) kidney disease; (IV) patients with preoperative hypercalcemia or hypocalcemia; (V) patients with preoperative hyperparathyroidism or hypoparathyroidism. Serum calcium and PTH levels, rates of hypocalcemia and hypoparathyroidism during 24 months follow-up were compared grouping by the number of parathyroid glands identified intraoperatively and the number of parathyroid glands confirmed postoperatively by pathology. Comparisons were also conducted in patients with 3 identified parathyroid glands grouping by autotransplantation and in situ preservation. PTC was finally confirmed by postoperative pathology.

\section{Surgical procedures}

All surgeries were performed by an experienced surgeon team and carbon nanoparticles suspension was injected into the thyroid gland to facilitate parathyroid glands identification according to patients' will (14). The indications for total thyroidectomy with bilateral central lymph node dissection are as follows: bilateral PTC; isthmus PTC; PTC with stage T3 or T4; prelaryngeal and/or pretracheal lymph node metastases; bilateral central lymph node or lateral lymph node metastases; TERT (+). There are usually three sources of blood supply to the upper parathyroid glands: (I) posterior branches of the upper thyroid artery, as the main blood supply source; (II) anastomotic branches of the upper and lower thyroid arteries; and (III) the lowest thyroid artery and the arteries at the larynx, trachea, esophagus, and so on. To ensure the parathyroid blood supply, the third-tier terminal blood vessels should be treated close to the natural thyroid capsule (true capsule), rather than ligating the trunk of the upper and lower thyroid arteries, which was called meticulous capsule dissection. During operation, attempt was firstly made to preserve all parathyroid glands and autotransplantation would be performed when the parathyroid gland was discolored at the end of the surgery or was incidentally removed during the operation, which would be chopped into $1 \mathrm{~mm}^{3}$ fragments and then autografted into several pockets in the ipsilateral sternocleidomastoid muscle. All the specimens removed would be systematically dissected in case intrathyroid parathyroid glands being unintentionally resected. Identification of parathyroid glands was based on visual features. The parathyroid gland would be verified by 
intraoperative frozen-section biopsy when in doubt. All surgical specimens were analyzed by the same pathologist and the presence of parathyroid glands accidentally resected in the surgical specimens was recorded.

\section{Perioperative evaluation and follow-up}

Demographic data were collected upon admission. Levels of serum calcium and parathyroid hormone (PTH) were measured at 1-day, 1-month, 3-month, 6-month, 12-month follow-up. Patients were given prophylactically intravenous 4,000 $\mathrm{mg}$ calcium gluconate supplementation after operation. Then patients with normal calcium complained no discomfort were discharged on the $1^{\text {st }}$ or $2^{\text {nd }}$ postoperative day. Patients were followed up in the outpatient department.

\section{Definition}

Postoperative hypoparathyroidism was defined as a PTH level $<14 \mathrm{pg} / \mathrm{mL}$ (normal range, 14-65 pg/mL), regardless of hypocalcemia symptoms. Transient hypoparathyroidism was defined as occurring for less than six months after surgery, while permanent hypoparathyroidism continued beyond six months after surgery. Postoperative hypocalcemia was defined as a serum calcium level $<8.5 \mathrm{mg} / \mathrm{dL}$ (normal range, $8.5-10.5 \mathrm{mg} / \mathrm{dL}$ ). The number of identified parathyroid glands was defined based on visual features or intraoperative frozen-section biopsy and the parathyroid glands had been preserved in situ or autotransplanted after that. We defined the actual number of parathyroid glands as the number of identified parathyroid glands in the condition of no accidentally resected parathyroid glands in the surgical specimens confirmed by pathological paraffin section examination.

\section{Data collection}

All data were collected retrospectively, including (I) Demographic data and basic information: age, sex, body mass index (BMI), nodular goiter (NG), Hashimoto's disease (HD), hypertension, diabetes, hyperthyroidism, hypothyroidism; (II) oncological data: tumor size, multifocality, TNM stage, capsule invasion; (III) Preoperative examination; (IV) the number of parathyroid glands identified, autotransplanted, resected in the surgical specimens was recorded in all cases. The levels of calcium and PTH at long-term follow-up, the rates of hypocalcemia and hypoparathyroidism were primary endpoints. American Joint Committee on Cancer (AJCC) staging (the 8th edition) was applied for all PTC patients $(15,16)$.

\section{Statistical analysis}

If normally distributed, continuous variables were expressed as mean \pm standard deviation and evaluated by the Student's $t$-test and/or analysis of variance; if not normally distributed, variables were presented as median (interquartile range) and compared by $\mathrm{U}$-test. The $\chi^{2}$ test or Fisher exact test was used to evaluate the differences of incidences. Based on the variables that were statistically significant or $\mathrm{P}$ value $<0.10$ in univariate analysis, multivariate analysis with logistic regression was conducted to identify the independent risk factors. The results of the multivariate analysis were reported as odds ratio (OR) with $95 \%$ confidence interval (CI). Two-sided $\mathrm{P}<0.05$ was considered statistically significant. All statistical analyses were performed using IBM SPSS Statistics version 25.0 for Windows (IBM Corp., Armonk, NY).

\section{Results}

\section{Patient characteristics}

Of the 2,032 patients whose medical records were reviewed, 1,424 patients were included with an age of $41.4 \pm 11.6$ years (Figure 1). The characteristics of patients were presented in Table 1. The duration of follow-up was $21.3 \pm 4.9$ months, with a range from 12 to 30 months, respectively. All patients underwent total thyroidectomy with bilateral central neck dissection. There were 1,042 (73.2\%) women and 382 (26.8\%) men. Among them, 340 (23.9\%) complicated with HD and $709(49.8 \%)$ complicated with NG. The mean size of the tumor was $14.1 \pm 8.9 \mathrm{~mm}$ and multifocality was identified in 347 (24.4\%) patients; 766 (53.8\%) patients were diagnosed with transient hypoparathyroidism and 21 $(1.5 \%)$ were permanent.

\section{Parathyroid glands identification and accidental resection}

Three parathyroid glands were identified in 212 (14.9\%) patients and four parathyroid glands were identified in $1,212(85.1 \%)$ patients. The final pathological examination presented $94(6.6 \%)$ cases with accidental resection of parathyroid glands, in which 2 cases were resected 2 parathyroid glands respectively. After excluding the 94 


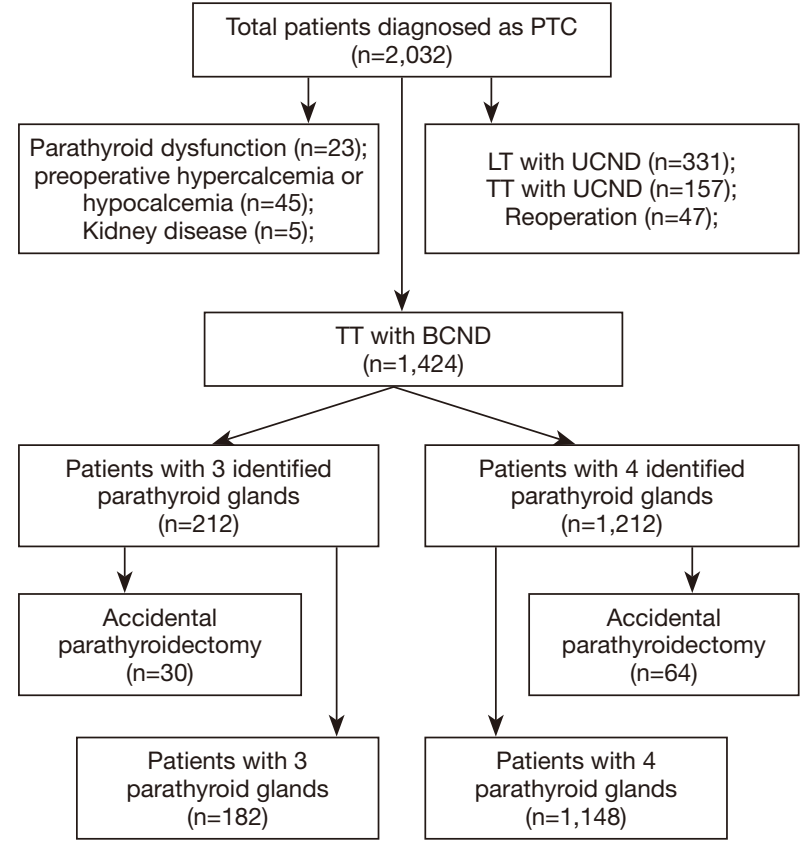

Figure 1 Flow chart of patients reviewed. PTC, papillary thyroid carcinoma; LT, lobectomy; TT, total thyroidectomy; UCND, unilateral central neck dissection; BCND, bilateral central neck dissection.

patients with accidently parathyroidectomy, 182 (13.7\%) patients were deemed to have actual 3 parathyroid glands and 1,148 (86.3\%) patients have 4. As seen in Table 2 and Table 3, no significant difference was found in age, sex, BMI, NG, tumor size, etc. However, higher rates of HD were observed in patients with 3 identified parathyroid glands compared with patients with $4(33.5 \%$ vs. $22.2 \%, \mathrm{P}<0.001)$, and similarly higher rates of HD were observed in patients whose actual number of parathyroid glands was 3 compared with whose number was $4(35.2 \%$ vs. $22.1 \%, \mathrm{P}<0.001)$. Meanwhile, the incidence of unintentionally resected parathyroid glands was $14.2 \%$ and $5.3 \%$ in patients with 3 and 4 identified parathyroid glands, respectively $(\mathrm{P}<0.001)$.

\section{Comparisons between patients with 3 and 4 identified parathyroid glands}

We compared the incidence of transient and permanent hypoparathyroidism, the serum PTH and calcium levels before the operation and after 2-year follow-up according to grouping by the number of parathyroid glands identified. The details were given in Table 2. No significant difference was found between these two groups in preoperative PTH
Table 1 Demographics and baseline characteristics of the sample

\begin{tabular}{|c|c|c|}
\hline Characteristics & Values & $\%$ \\
\hline Age, years & $41.4 \pm 11.6$ & - \\
\hline Sex, male/female & $382 / 1,042$ & $26.8 / 73.2$ \\
\hline BMI & $23.1 \pm 3.9$ & - \\
\hline$N G$ & 709 & 49.8 \\
\hline HD & 340 & 23.9 \\
\hline Hypertension & 117 & 8.2 \\
\hline Diabetes & 45 & 3.2 \\
\hline Hypothyroidism & 26 & 1.8 \\
\hline Hyperthyroidism & 34 & 2.4 \\
\hline Tumor size (mm) & $14.1 \pm 8.9$ & - \\
\hline Multifocality & 347 & 24.4 \\
\hline Capsule invasion & 586 & 41.2 \\
\hline \multicolumn{3}{|l|}{ TNM stage } \\
\hline $\mathrm{Tx} / \mathrm{T} 1 / \mathrm{T} 2 / \mathrm{T} 3 / \mathrm{T} 4$ & 8/756/92/501/66 & 6.0/53.1/6.5/35.2/4.6 \\
\hline $\mathrm{Nx} / \mathrm{N} 0 / \mathrm{N} 1 \mathrm{a} / \mathrm{N} 1 \mathrm{~b}$ & $9 / 573 / 484 / 356$ & $0.6 / 40.2 / 34.0 / 25.0$ \\
\hline $\begin{array}{l}\text { No. of identified } \\
\text { PGs }(3 / 4)\end{array}$ & $212 / 1212$ & $14.9 / 85.1$ \\
\hline Accidental resection & 94 & 6.6 \\
\hline $\begin{array}{l}\text { No. of PGs after } \\
\text { excluding accidental } \\
\text { resection }(3 / 4)\end{array}$ & $182 / 1,148$ & $13.7 / 86.3$ \\
\hline \multicolumn{3}{|l|}{ Hypoparathyroidism } \\
\hline Transient & 766 & 53.8 \\
\hline Permanent & 21 & 1.5 \\
\hline
\end{tabular}

BMI, body mass index; HD, Hashimoto's disease; NG, nodular goiter; TNM, tumor node metastasis; No. of identified PGs, number of identified parathyroid glands; No. of PGs, number of parathyroid glands with no accidental resection.

$(\mathrm{P}=0.079)$ and calcium levels $(\mathrm{P}=0.188)$. These two groups had comparable rates of transient $(\mathrm{P}=0.770)$ and permanent hypoparathyroidism $(\mathrm{P}=1.000)$.

Compared to patients with 4 identified parathyroid glands, those with 3 had lower levels of serum PTH $(\mathrm{pg} / \mathrm{mL})$ at postoperative 1-month, 3-month and 6-month $(29.88 \pm 11.43$ vs. $34.65 \pm 13.77, \mathrm{P}<0.001 ; 32.85 \pm 13.59$ vs. $37.71 \pm 14.40, \mathrm{P}=0.008$ and $34.02 \pm 12.78$ vs. $38.25 \pm 13.23$, $\mathrm{P}=0.015$; respectively) (Figure $2 A$ ). Although the difference did not appear to be statistically significant, PTH $<14 \mathrm{pg} / \mathrm{mL}$ was more frequent in patients with 3 identified 
Table 2 Comparisons between patients with 3 and 4 identified parathyroid glands

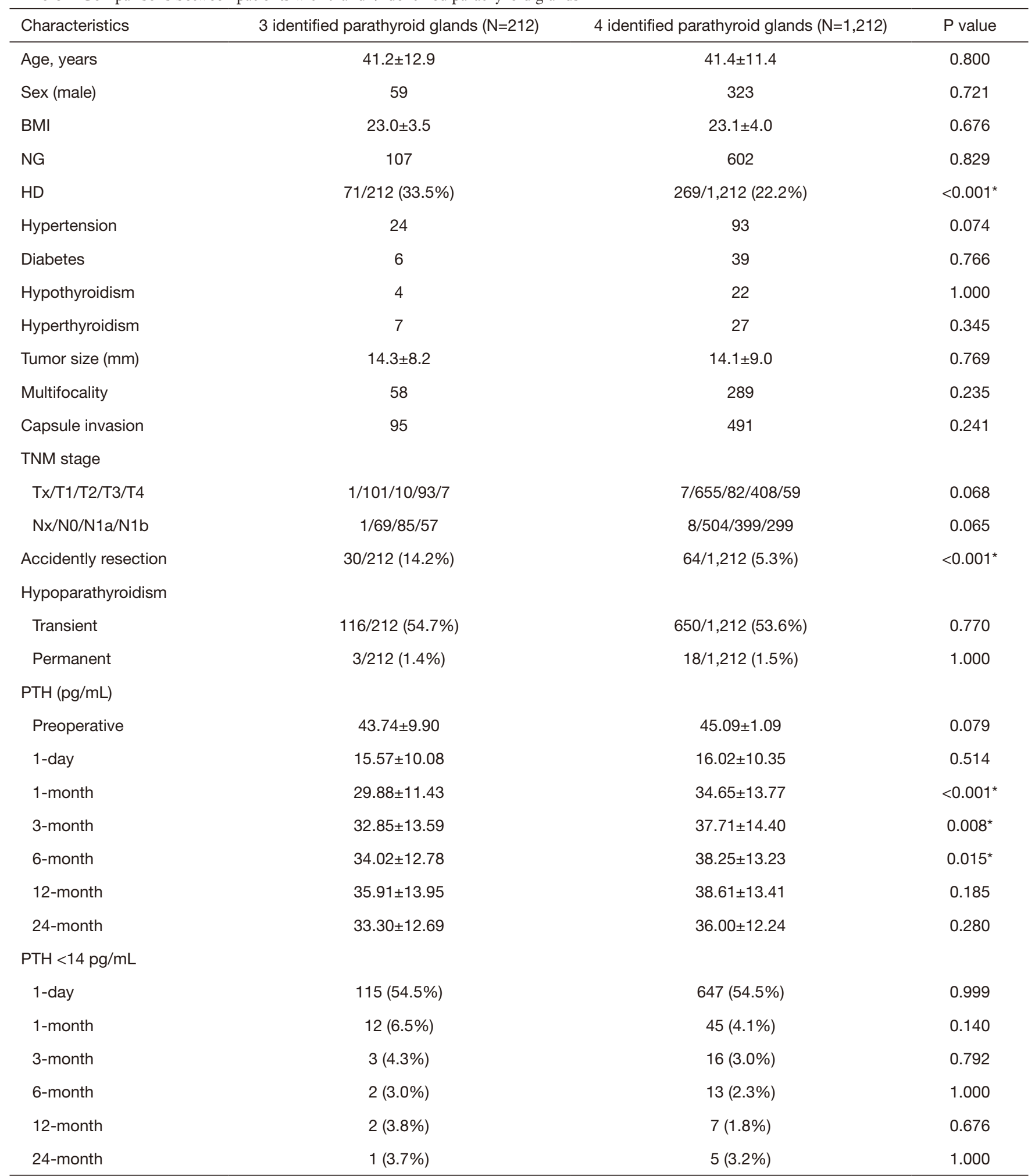

Table 2 (continued) 
Table 2 (continued)

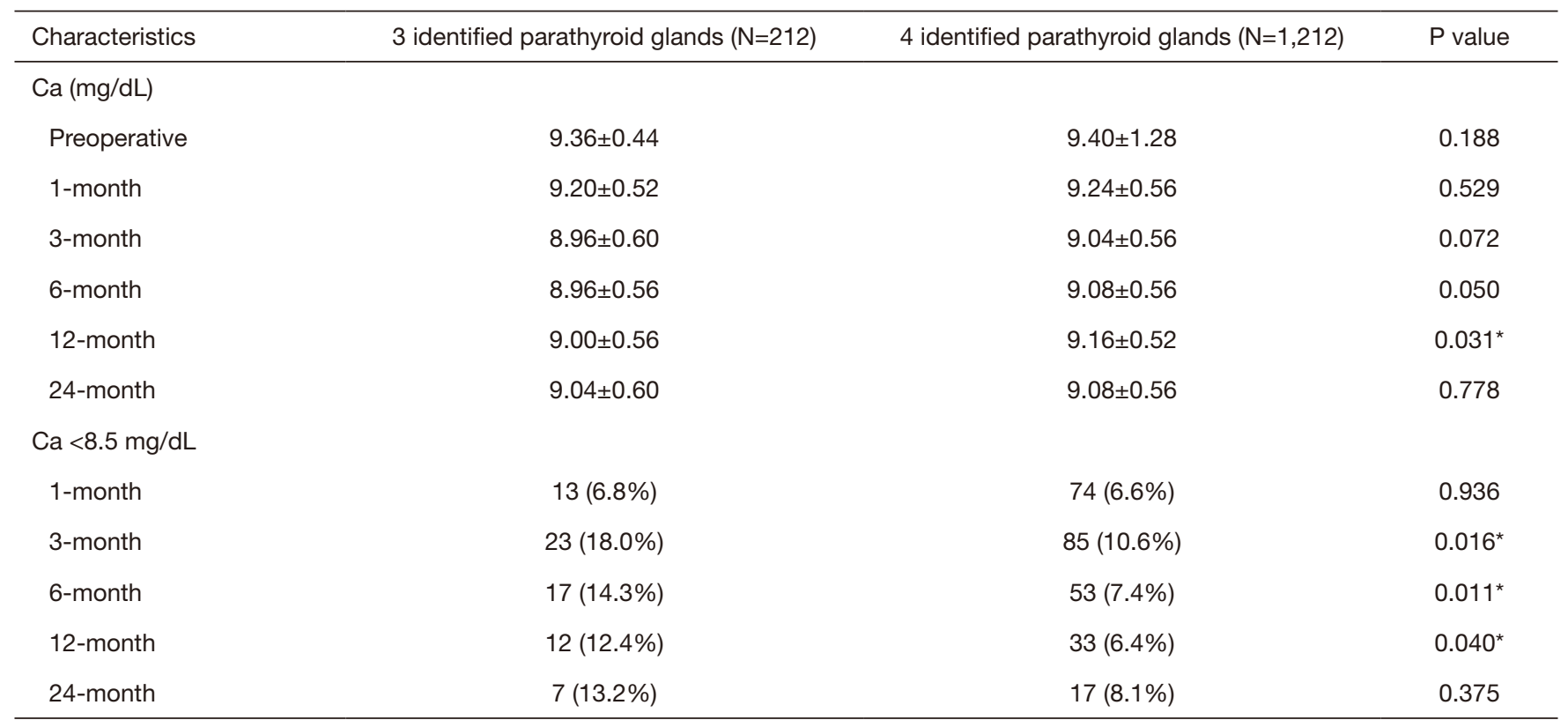

*, significantly statistical differences. BMI, body mass index; HD, Hashimoto's disease; NG, nodular goiter; TNM, tumor node metastasis; PTH, parathyroid hormone; $\mathrm{Ca}$, calcium.

parathyroid glands during 2-year follow-up.

As for serum calcium ( $\mathrm{mg} / \mathrm{dL})$, lower levels were observed in patients with 3 identified parathyroid glands at postoperative 12 -month $(9.00 \pm 0.56$ vs. $9.16 \pm 0.52, \mathrm{P}=0.031)$. Meanwhile, hypocalcemia was incrementally more common in patients with 3 identified parathyroid glands at postoperative 3-month, 6-month and 12-month (18.0\% vs. $10.6 \%, \mathrm{P}=0.016 ; 14.3 \%$ vs. $7.4 \%, \mathrm{P}=0.011 ; 12.4 \%$ vs. $6.4 \%$, $\mathrm{P}=0.040$; respectively).

\section{Comparisons between patients with 3 and 4 parathyroid glands with no accidently resection}

The comparisons of patients with 3 and 4 parathyroid glands with no accidently resection were summarized in Table 3. Though preoperative calcium levels did not differ between these two groups $(\mathrm{P}=0.175)$, lower levels of preoperative PTH $(\mathrm{pg} / \mathrm{mL})$ were observed in patients with 3 parathyroid glands versus patients with $4(43.29 \pm 9.90$ vs. $45.00 \pm 9.81, \mathrm{P}=0.034)$. The rates of transient $(\mathrm{P}=0.770)$ and permanent $(\mathrm{P}=1.000)$ hypoparathyroidism were comparable in these two groups.

Compared to patients with 4 parathyroid glands, those with 3 were highly correlated with lower levels of serum PTH $(\mathrm{pg} / \mathrm{mL})$ at postoperative 1-month, 3-month and 6-month $(29.43 \pm 11.16$ vs. $34.83 \pm 13.86, \mathrm{P}<0.001$; $32.76 \pm 13.05$ vs. $37.89 \pm 14.40, \mathrm{P}=0.009 ; 33.66 \pm 12.51$ vs. $38.43 \pm 13.23, \mathrm{P}=0.009$; respectively) (Figure $2 B$ ).

As for the serum calcium, compared to patients with 4 parathyroid glands identified, higher rates of hypocalcemia at postoperative 3 -month $(16.5 \%$ vs. $10.1 \%, \mathrm{P}=0.038)$ were observed in patients with 3 parathyroid glands. There was a trend to higher incidence of PTH $<14 \mathrm{pg} / \mathrm{mL}$ and hypocalcemia during 2-year follow-up in patients with 3 parathyroid glands, though it did not differ significantly.

\section{Comparisons in patients with 3 identified parathyroid glands}

Of 212 patients with 3 identified parathyroid glands, autotransplantation of more than one parathyroid gland was performed in 138 , with a mean number of $1.17 \pm 0.417$ parathyroid glands, and parathyroid glands of the other 74 patients were all preserved in situ. Significantly lower levels of PTH $(14.22 \pm 9.54$ vs. $17.91 \pm 10.80, \mathrm{P}=0.011)$ and higher rates of PTH $<14 \mathrm{pg} / \mathrm{mL}(63.5 \%$ vs. $37.8 \%$, $\mathrm{P}<0.001)$ at postoperative 1 -day, higher rates of transient hypoparathyroidism within 6 months $(63.0 \%$ vs. $39.2 \%$, $\mathrm{P}=0.001)$ were observed in the autotransplanted group compared with non-autotransplanted group (Table 4). 
Table 3 Comparisons between patients with 3 and 4 parathyroid glands with no accidental resection

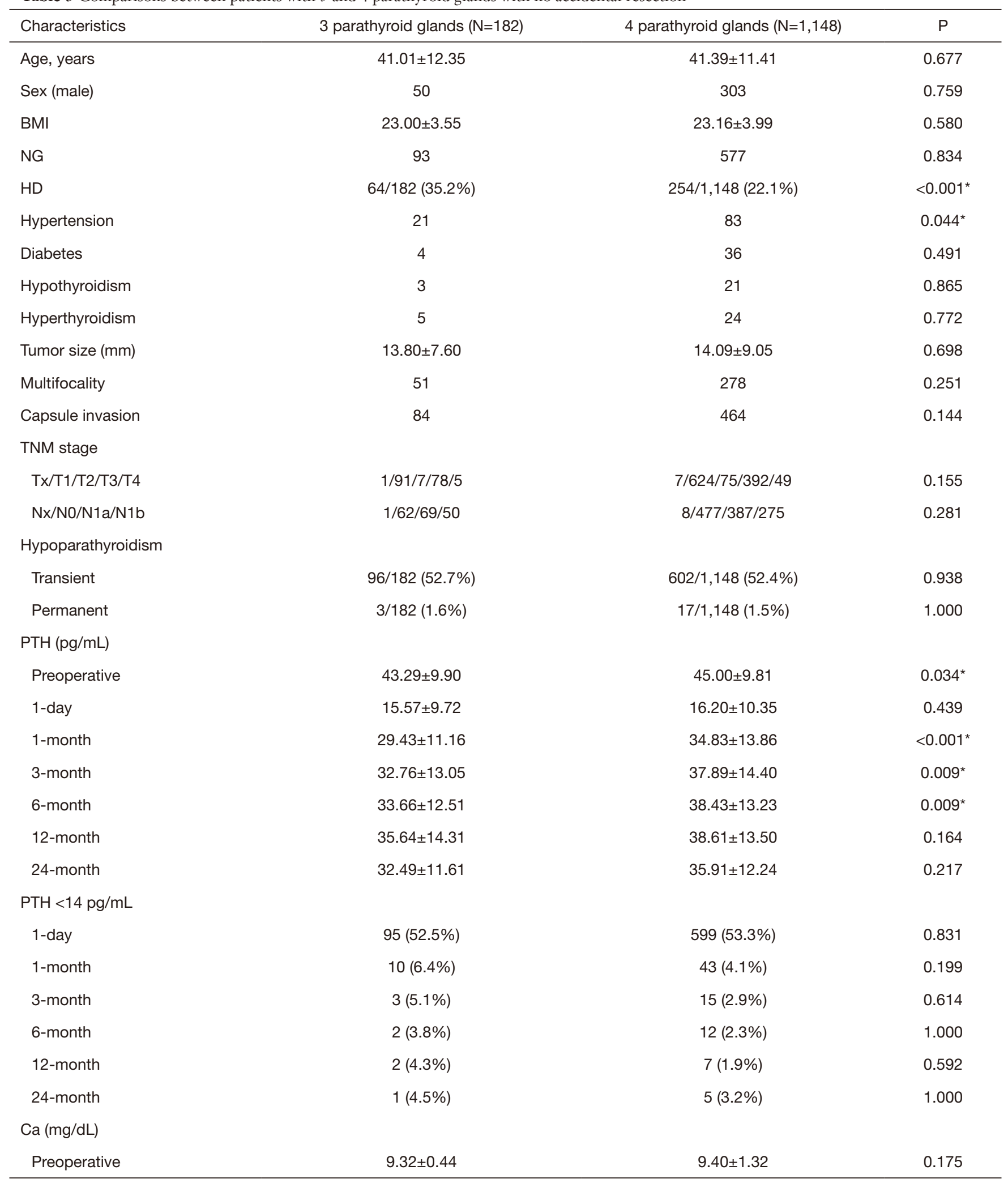

Table 3 (continued) 
Table 3 (continued)

\begin{tabular}{|c|c|c|c|}
\hline Characteristics & 3 parathyroid glands $(\mathrm{N}=182)$ & 4 parathyroid glands $(\mathrm{N}=1,148)$ & $\mathrm{P}$ \\
\hline 3-month & $8.96 \pm 0.60$ & $9.08 \pm 0.56$ & 0.092 \\
\hline 6-month & $2.25 \pm 0.14$ & $9.08 \pm 0.56$ & 0.100 \\
\hline 12-month & $2.26 \pm 0.13$ & $9.12 \pm 0.52$ & 0.099 \\
\hline \multicolumn{4}{|l|}{$\mathrm{Ca}<8.5 \mathrm{mg} / \mathrm{dL}$} \\
\hline 1-month & $10(6.2 \%)$ & $62(5.9 \%)$ & 0.872 \\
\hline 3-month & $18(16.5 \%)$ & $77(10.1 \%)$ & $0.045^{\star}$ \\
\hline 6-month & $12(11.8 \%)$ & $48(7.0 \%)$ & 0.094 \\
\hline
\end{tabular}

*, significantly statistical differences. BMI, body mass index; HD, Hashimoto's disease; NG, nodular goiter; TNM, tumor node metastasis; PTH, parathyroid hormone; Ca, calcium.
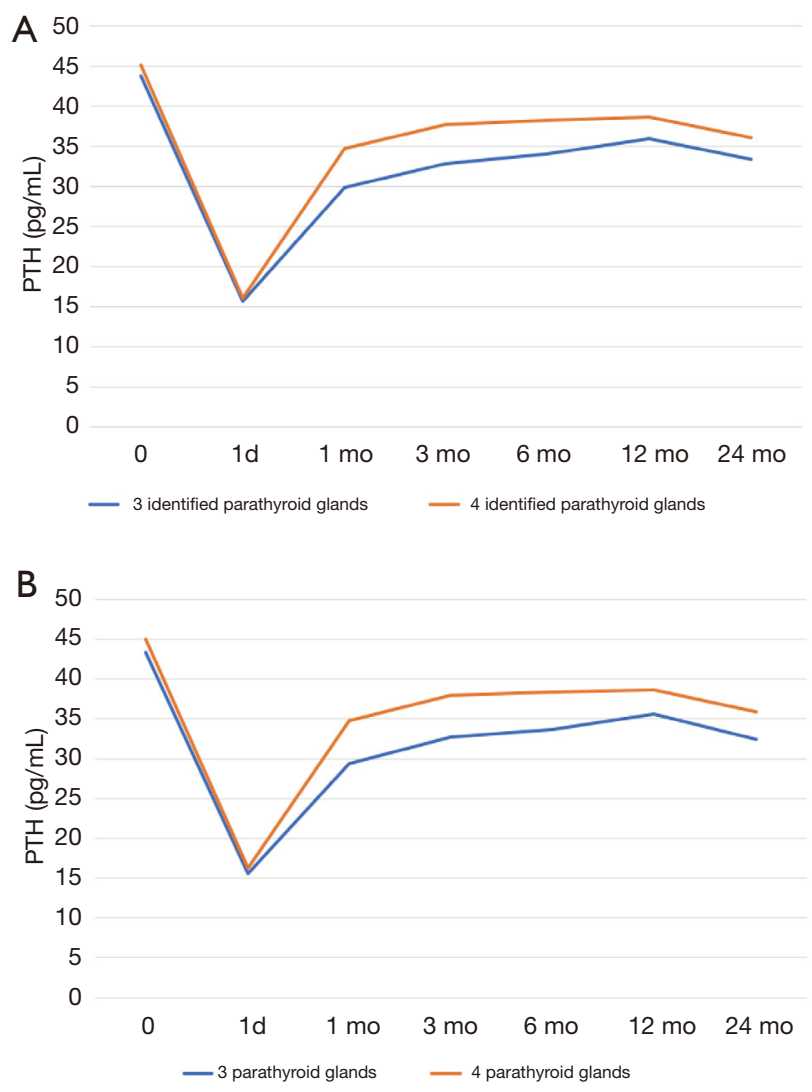

Figure 2 Trend of PTH levels. (A) PTH levels of patients with 3 and 4 identified parathyroid glands. (B) PTH levels of patients with no accidental parathyroidectomy. PTH, parathyroid hormone.
Although the incidence of permanent hypoparathyroidism did not reach statistical difference between these two groups, the levels of PTH $(\mathrm{pg} / \mathrm{mL})$ at postoperative 12 -month in patients underwent autotransplantation were significantly lower than patients underwent no autotransplantation $(32.85 \pm 11.70$ vs. $42.03 \pm 17.01, \mathrm{P}=0.026)$.

\section{Risk factors for hypoparathyroidism}

Number of identified parathyroid glands, autotransplantation, accidental resection, sex, age, HD, NG, hypothyroidism, hyperthyroidism tumor size, multifocality, capsule invasion, preoperative calcium and $\mathrm{PTH}, \mathrm{TNM}$ stage were included in univariate and multivariate analyses. Multivariate analysis found autotransplantation (OR, 2.047; 95\% CI, $1.557-$ 2.764; $\mathrm{P}<0.001)$, accidental resection (OR, 2.379; 95\% CI, 1.480-3.824; $\mathrm{P}<0.001)$, HD (OR, 1.436; 95\% CI, $1.113-$ 1.852; $\mathrm{P}=0.005)$ to be independent risk factors of transient hypoparathyroidism, while three identified parathyroid glands (OR, 1.134; 95\% CI, 0.830-1.549; $\mathrm{P}=0.430$ ) was not. No dependent risk factor of permanent hypoparathyroidism was found.

\section{Discussion}

Hypocalcemia after total thyroidectomy is caused by a decrease in circulating PTH, which is result from a reduction 
Table 4 Comparisons in patients with 3 identified parathyroid glands

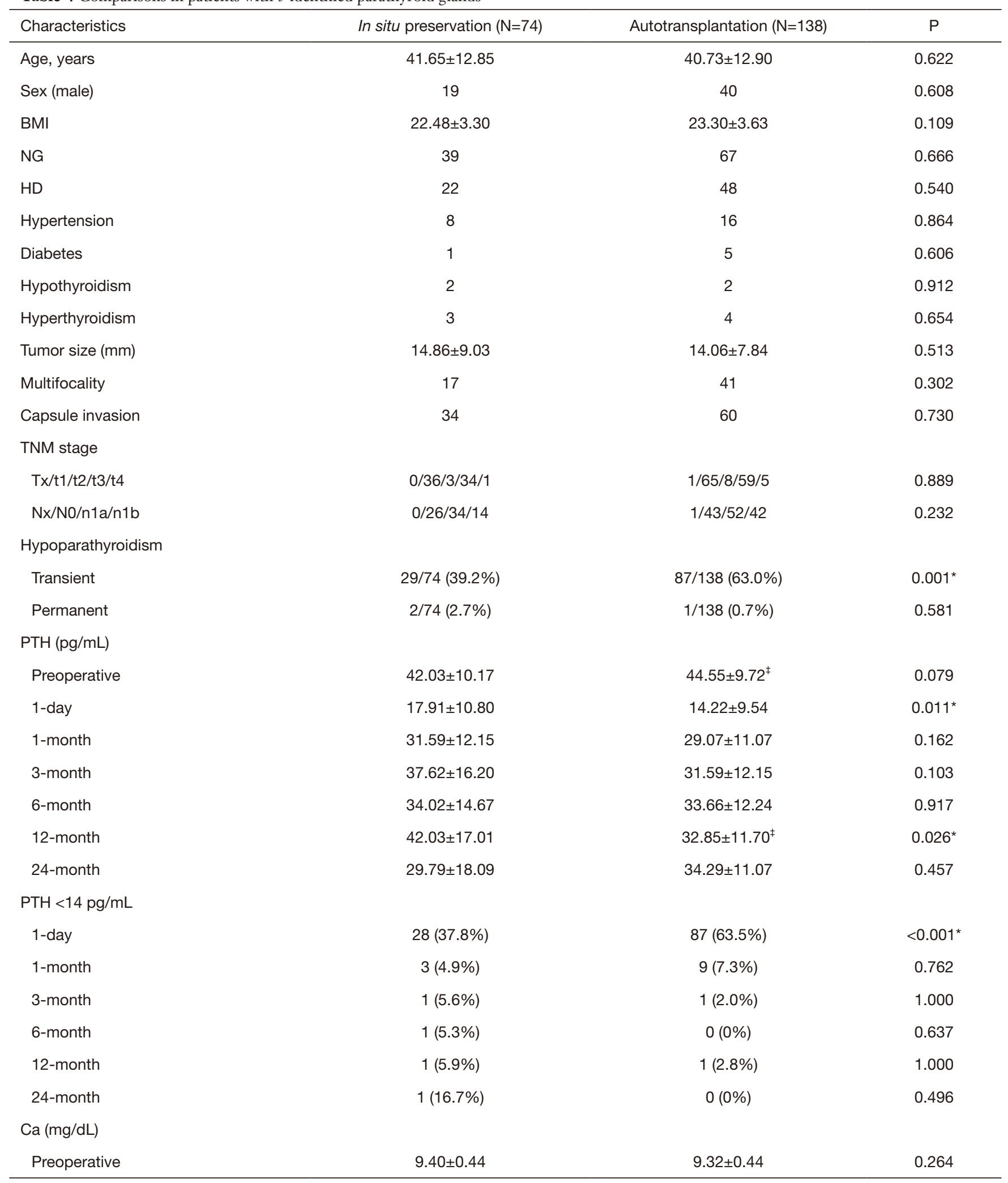

Table 4 (continued) 
Table 4 (continued)

\begin{tabular}{|c|c|c|c|}
\hline Characteristics & In situ preservation $(\mathrm{N}=74)$ & Autotransplantation $(\mathrm{N}=138)$ & $\mathrm{P}$ \\
\hline 3-month & $8.96 \pm 0.68$ & $8.92 \pm 0.56$ & 0.763 \\
\hline 6-month & $8.92 \pm 0.68$ & $9.04 \pm 0.72$ & 0.258 \\
\hline 12-month & $9.00 \pm 0.52$ & $9.00 \pm 0.60$ & 0.988 \\
\hline \multicolumn{4}{|l|}{$\mathrm{Ca} 8.5 \mathrm{mg} / \mathrm{dL}$} \\
\hline 1-month & $3(4.5 \%)$ & $10(8.0 \%)$ & 0.549 \\
\hline 3-month & $8(19.5 \%)$ & $15(17.4 \%)$ & 0.777 \\
\hline 6-month & $8(21.1 \%)$ & $9(11.3 \%)$ & 0.157 \\
\hline
\end{tabular}

${ }^{*}$, significantly statistical differences; ${ }^{\ddagger}$, the difference of PTH levels between preoperative and postoperative 12-month in patients with autotransplantation reached statistical significance. BMI, body mass index; HD, Hashimoto's disease; NG, nodular goiter; TNM, tumor node metastasis; PTH, parathyroid hormone; Ca, calcium.

of parathyroid parenchyma function $(17,18)$. Some studies have reported that the fewer identified parathyroid glands at operation, the higher the risk of postoperative hypocalcemia and permanent hypoparathyroidism, which may result from accidental parathyroidectomy $(2,19,20)$. This was not completely consistent with our results. Our present study demonstrated no correlation between 3 identified parathyroid glands and transient or permanent hypoparathyroidism. Due to potential disturbance of prophylactically calcium supplementation after operation, calcium levels at postoperative 1-day was not conducted. However, the levels of PTH and calcium were nearly lower and hypocalcemia trend was higher in patients with 3 identified parathyroid glands compared with patients with 4 at all follow-up stages, and some of them reached statistical difference.

The results of our study suggested that this was not totally due to accidental parathyroid glands resection, and our opinion was supported by some studies which revealed no correlation between inadvertent parathyroid resection and permanent hypoparathyroidism (21). Because we reached similar results after excluding patients with accidental parathyroid resection that the function recovery based on PTH and calcium levels in patients with 3 parathyroid glands was poorer. However, we could not deny the influence of accidental parathyroid resection because it is always reported to add a further risk of postoperative transient and permanent hypoparathyroidism $(17,22,23)$.
We hold the opinion that the parathyroid glands function of patients with 3 glands was weaker than patients with 4 essentially, which was proved by lower preoperative PTH levels in patients with 3 parathyroid glands. Meanwhile, the results of the present study suggested that the incidence of accidental parathyroid resection was only $14.3 \%$ in patients with 3 identified parathyroid glands intraoperatively, and other $85.7 \%$ patients own three parathyroid glands originally. Therefore, surgeons should be more cautious when only 3 parathyroid glands were identified during operation. However, some experts have suggested that parathyroid gland identification had no influence on rates of hypocalcemia or even that identification might have an adverse effect (24-28). Some experts recommended that nano-carbon negative parathyroid development technology could help identify and protect parathyroid glands during surgery and could reduce the incidence of postoperative hypoparathyroidism (29).

As reported in the previous studies, autotransplantation of parathyroid gland did not affect the incidence of permanent hypoparathyroidism, but increased the risk of transient hypoparathyroidism (30), which was consistent with the results of this present study. A study included 1,196 patients demonstrated that the incidence of permanent hypoparathyroidism was $0.98 \%, 0.77 \%$, $0.97 \%$ and $0 \%$ in patients with $0,1,2,3$ parathyroid glands autotransplanted respectively, suggesting no 
significant difference (31). Some authors believed that autotransplantation may be the best strategy to prevent permanent hypoparathyroidism despite an increase of short-term hypocalcemia (31-33). In our study, the PTH levels were always lower in patients with parathyroid glands autotransplanted compared with all preserved in situ during postoperative follow-up, and the difference reached statistical significance at postoperative 12-month. Only at 24-month follow-up did the opposite result occur, which might be due to relative more patients lost followup at 24-month. What's more, preoperative PTH levels and postoperative 12 -month PTH levels were similar in patients whose parathyroid glands were preserved all in situ, while it was lower at postoperative 12-month than preoperative in patients with autotransplantation. This indicated that parathyroid function was not fully restored to the preoperative level in patients with autotransplantation. Scholars from Japan reported the overall incidence of permanent hypoparathyroidism in the preservation group and the autotransplantation group was $0 \%$ and $21.4 \%$ respectively, and the mean levels of PTH recovered to $102 \%$ in the preservation group but only $50 \%$ in the autotransplantation group of the preoperative levels at 5-year follow up (34). Su et al. demonstrated that in situ preservation of less than 2 parathyroid glands was a significant variable favoring permanent hypoparathyroidism (30). The results of the present study supported that parathyroid glands should be preserved in situ whenever possible to promote better recovery of postoperative function, especially for patients with fewer identified parathyroid glands.

There are some limitations in the present study. First, the data was retrieved retrospectively which might leaded to some bias. Second, there might be some missing description inevitably in the surgical records resulting in higher incidence of 4 parathyroid glands identification due to the doubt situation might be recorded as "all 4 glands were identified". Third, although all the specimens removed would be systematically dissected in case of intrathyroid parathyroid glands being unintentionally resected, possibility of unidentified or ectopic parathyroid were still present. The other limitation is the short follow-up time, resulting in the inability to observe more than 2-year parathyroid function.

\section{Conclusions}

The parathyroid glands function was weaker in patients with
3 glands than patients with 4 before and after operation. Parathyroid glands should be tried to be preserved in situ to promote better recovery of postoperative function, especially for patients with three identified parathyroid glands.

\section{Acknowledgments}

Funding: None.

\section{Footnote}

Reporting Checklist: The authors have completed the STROBE reporting checklist. Available at http://dx.doi. org/10.21037/gs-20-486

Data Sharing Statement: Available at http://dx.doi. org/10.21037/gs-20-486

Peer Review File: Available at http://dx.doi.org/10.21037/gs20-486

Conflicts of Interest: All authors have completed the ICMJE uniform disclosure form (available at http://dx.doi. org/10.21037/gs-20-486). The authors have no conflicts of interest to declare.

Etbical Statement: The authors are accountable for all aspects of the work in ensuring that questions related to the accuracy or integrity of any part of the work are appropriately investigated and resolved. The study was conducted in accordance with the Declaration of Helsinki (as revised in 2013). The Institutional Review Board of West China Hospital (No. 2019-799) approved this retrospective study, and all patients provided informed consent to have their data recorded, analyzed, and published for research purposes.

Open Access Statement: This is an Open Access article distributed in accordance with the Creative Commons Attribution-NonCommercial-NoDerivs 4.0 International License (CC BY-NC-ND 4.0), which permits the noncommercial replication and distribution of the article with the strict proviso that no changes or edits are made and the original work is properly cited (including links to both the formal publication through the relevant DOI and the license). See: https://creativecommons.org/licenses/by-nc$\mathrm{nd} / 4.0 /$. 


\section{References}

1. Qiu Y, Fei Y, Liu J, et al, Prevalence, Risk Factors And Location Of Skip Metastasis In Papillary Thyroid Carcinoma: A Systematic Review And Meta-Analysis. Cancer Manag Res 2019;11:8721-30.

2. Bergenfelz A, Jansson S, Kristoffersson A, et al. Complications to thyroid surgery: results as reported in a database from a multicenter audit comprising 3,660 patients. Langenbecks Arch Surg 2008;393:667-73.

3. Fahad Al-Dhahri S, Al-Ghonaim YA, Sulieman Terkawi A. Accuracy of postthyroidectomy parathyroid hormone and corrected calcium levels as early predictors of clinical hypocalcemia. J Otolaryngol Head Neck Surg 2010;39:342-8.

4. Bliss RD, Gauger PG, Delbridge LW. Surgeon's approach to the thyroid gland: surgical anatomy and the importance of technique. World J Surg 2000;24:891-7.

5. Docimo G, Ruggiero R, Casalino G, et al. Risk factors for postoperative hypocalcemia. Updates Surg 2017;69:255-60.

6. Shan CX, Zhang W, Jiang DZ, et al. Routine central neck dissection in differentiated thyroid carcinoma: a systematic review and meta-analysis. Laryngoscope 2012;122:797-804.

7. Edafe O, Antakia R, Laskar N, et al. Systematic review and meta-analysis of predictors of post-thyroidectomy hypocalcaemia. Br J Surg 2014;101:307-20.

8. Giordano D, Valcavi R, Thompson GB, et al, Complications of central neck dissection in patients with papillary thyroid carcinoma: results of a study on 1087 patients and review of the literature. Thyroid 2012;22:911-7.

9. Lorente-Poch L, Sancho JJ, Ruiz S, et al. Importance of in situ preservation of parathyroid glands during total thyroidectomy. Br J Surg 2015;102:359-67.

10. Ahmed N, Aurangzeb M, Muslim M, et al. Routine parathyroid autotransplantation during total thyroidectomy: a procedure with predictable outcome. J Pak Med Assoc 2013;63:190-3.

11. Funahashi H, Satoh Y, Imai T, et al. Our technique of parathyroid autotransplantation in operation for papillary thyroid carcinoma. Surgery 1993;114:92-6.

12. Hojaij F, Vanderlei F, Plopper C, et al. Parathyroid gland anatomical distribution and relation to anthropometric and demographic parameters: a cadaveric study. Anat Sci Int 2011;86:204-12.

13. von Elm E, Altman DG, Egger M, et al. The
Strengthening the Reporting of Observational Studies in Epidemiology (STROBE) Statement: guidelines for reporting observational studies. Int J Surg 2014;12:1495-9

14. Li J, Li X, Wang Z. Negative developing of parathyroid using carbon nanoparticles during thyroid surgery. Gland Surg 2013;2:100-1.

15. Haddad R I, Nasr C, Bischoff L, et al. NCCN Guidelines Insights: Thyroid Carcinoma, Version 2.2018. J Natl Compr Canc Netw 2018;16:1429-40.

16. Zanoni DK, Patel SG, Shah JP. Changes in the 8th Edition of the American Joint Committee on Cancer (AJCC) Staging of Head and Neck Cancer: Rationale and Implications. Curr Oncol Rep 2019;21:52.

17. Paek SH, Lee YM, Min SY, et al. Risk factors of hypoparathyroidism following total thyroidectomy for thyroid cancer. World J Surg 2013;37:94-101.

18. Barczyński M, Cichoń S, Konturek A. Which criterion of intraoperative iPTH assay is the most accurate in prediction of true serum calcium levels after thyroid surgery? Langenbecks Arch Surg 2007;392:693-8.

19. Thomusch O, Machens A, Sekulla C, et al. The impact of surgical technique on postoperative hypoparathyroidism in bilateral thyroid surgery: a multivariate analysis of 5846 consecutive patients. Surgery 2003;133:180-5.

20. Wilson RB, Erskine C, Crowe PJ. Hypomagnesemia and hypocalcemia after thyroidectomy: prospective study. World J Surg 2000;24:722-6.

21. Song CM, Jung JH, Ji YB, et al. Relationship between hypoparathyroidism and the number of parathyroid glands preserved during thyroidectomy. World J Surg Oncol 2014;12:200.

22. Mann B, Buhr HJ. Lymph node dissection in patients with differentiated thyroid carcinoma--who benefits? Langenbecks Arch Surg 1998;383:355-8.

23. Cho JN, Park WS, Min SY. Predictors and risk factors of hypoparathyroidism after total thyroidectomy. Int J Surg 2016;34:47-52.

24. Hallgrimsson P, Nordenström E, Almquist M, et al. Risk factors for medically treated hypocalcemia after surgery for Graves' disease: a Swedish multicenter study of 1,157 patients. World J Surg 2012;36:1933-42.

25. Lang BH, Yih PC, Ng KK. A prospective evaluation of quick intraoperative parathyroid hormone assay at the time of skin closure in predicting clinically relevant hypocalcemia after thyroidectomy. World J Surg 2012;36:1300-6.

26. Vanderlei FA, Vieira JG, Hojaij FC, et al. Parathyroid hormone: an early predictor of symptomatic hypocalcemia 
after total thyroidectomy. Arq Bras Endocrinol Metabol 2012;56:168-72.

27. Pfleiderer AG, Ahmad N, Draper MR, et al. The timing of calcium measurements in helping to predict temporary and permanent hypocalcaemia in patients having completion and total thyroidectomies. Ann R Coll Surg Engl 2009;91:140-6.

28. Sheahan $\mathrm{P}$, Mehanna $\mathrm{R}$, Basheeth $\mathrm{N}$, et al. Is systematic identification of all four parathyroid glands necessary during total thyroidectomy?: a prospective study. Laryngoscope 2013;123:2324-8.

29. Zhu J, Tian W, Xu Z, et al. Expert consensus statement on parathyroid protection in thyroidectomy. Ann Transl Med 2015;3:230.

30. Su A, Gong Y, Wu W, et al. Effect of autotransplantation of a parathyroid gland on hypoparathyroidism after total thyroidectomy. Endocr Connect 2018;7:286-94.

Cite this article as: Xing Z, Qiu Y, Xia B, Abuduwaili M, Fei Y, Zhu J, Su A. Surgical strategy when identifying less than four parathyroid glands during total thyroidectomy: a retrospective cohort study. Gland Surg 2021;10(1):10-22. doi: 10.21037 /gs-20-486
31. Palazzo FF, Sywak MS, Sidhu SB, et al. Parathyroid autotransplantation during total thyroidectomy--does the number of glands transplanted affect outcome? World J Surg 2005;29:629-31.

32. El-Sharaky MI, Kahalil MR, Sharaky O, et al. Assessment of parathyroid autotransplantation for preservation of parathyroid function after total thyroidectomy. Head Neck 2003;25:799-807.

33. Roh JL, Park JY, Park CI. Total thyroidectomy plus neck dissection in differentiated papillary thyroid carcinoma patients: pattern of nodal metastasis, morbidity, recurrence, and postoperative levels of serum parathyroid hormone. Ann Surg 2007;245:604-10.

34. Kihara M, Miyauchi A, Kontani K, et al. Recovery of parathyroid function after total thyroidectomy: long-term follow-up study. ANZ J Surg 2005;75:532-6. 